\title{
DOSSIÊ: PERSPECTIVAS QUEER NOS ESTUDOS DA LINGUAGEM
}

\section{RETÓRICA ANTIGÊNERO E ORDEM PÚBLICA: A CRUZADA DAS CRIANÇAS}

(Antigender Rhetoric and Public Order: The Children's Crusade)

Pablo Pérez Navarro ${ }^{1}$

(Centro de Estudos Sociais da Universidade de Coimbra)

Recebido em: novembro de 2020

Aceito em: dezembro de 2020

DOI: $10.26512 /$ les.v21i2.35158

\footnotetext{
${ }^{1}$ Doutor em Filosofia pela Universidade de La Laguna (Espanha) e investigador do Centro de Estudos Sociais (CES) da Universidade de Coimbra. Atualmente é professor visitante do Núcleo de Direitos Humanos e Cidadania LGBTQ $(\mathrm{NuH})$ da Universidade Federal de Minas Gerais. É o autor de Del texto al sexo: Judith Butler y la performatividad (Egales, 2008).
} 
Grande parte da energia de atenção e demarcação que girou em torno de questões relativas à homossexualidade desde o final do século XIX, na Europa e nos EUA, foi impulsionada pela relação distintivamente indicativa entre homossexualidade e mapeamentos mais amplos do segredo e da revelação, do privado e do público, que eram e são criticamente problemáticos para as estruturas econômicas, sexuais e de gênero da cultura heterossexista como um todo; mapeamentos cuja incoerência capacitadora, mas perigosa, foi condensada de maneira opressiva e duradoura em certas figuras da homossexualidade.

Eve Kosofsky Sedgwick, A epistemologia do armário

The act, an enigmatic and problematic production of the speaking body, destroys from its inception the metaphysical dichotomy between the domain of the "mental" and the domain of the "physical," breaks down the opposition between body and spirit, between matter and language.

Shoshana Felman, The scandal of the speaking body

\title{
RESUMO
}

O ar de família dos movimentos antigênero resulta da sua tentativa de transformar as exclusões constitutivas do campo genérico e sexual em princípios reguladores da ordem pública. Para ilustrar essa relação, a discussão que segue interpreta a retórica censora da Secretaria de Ordem Pública de Rio de Janeiro como uma tentativa de disciplinamento do espaço da coabitação na qual se confunde a censura corporal e a estritamente discursiva. Esta interseção será tomada, ademais, como ponto de partida para assinalar a indistinção entre o policiamento moral e securitário do espaço urbano inscritas na genealogia europeia da noção de ordem pública.

Palavras-chave: Retórica Antigênero. Ordem Pública. Cruzada das Crianças.

\begin{abstract}
Family resemblance of anti-gender movements result from the attempt to transform the constitutive exclusions of the fields of gender and sexuality in regulatory principles of the public order. In order to illustrate that relationship, the following discussion reads the censorship rhetorics of Rio de Janeiro's Public Order Secretariat as a tentative to discipline the space of cohabitation that blurs bodily and strictly discursive censorship. Further, this intersection will be taken as a departing point to explore the overlapping among moral and securitarian policing of urban space inscribed in the European genealogy of the notion of public order.
\end{abstract}

Abstract: Antigender Rhetoric. Public Order. Children's Crusade.

\section{RESUMEN}

Los movimientos anti-género adquieren su aire de familia de la tentativa de transformar las exclusiones constitutivas del campo genérico y sexual en principios reguladores del orden público. Para ilustrar esta intuición, la siguiente discusión interpreta la retórica censora de la Secretaría de Orden Público de Río de Janeiro como una tentativa de disciplinamiento del espacio de la cohabitación en la que se confunden la censura corporal y la estrictamente discursiva. Además, esta intersección será tomada como punto de partida para señalar la indistinción entre la vigilancia moral y securitaria del espacio urbano inscrita en la genealogía europea de la noción de orden público.

Key-words: Movimientos Anti-género. Orden Público. Cruzada de ninõs. 


\section{INTRODUÇÃO}

Resulta inegável, nesta altura, que a retórica das cruzadas antigênero apresenta uma capacidade camaleônica para se inserir nos mais diversos contextos geopolíticos. Longe de ficar confinados em quaisquer instituições religiosas, e apesar de ter sido descrita como "uma cruzada católica que se nega como tal" (PREARO; GARBAGNOLI, 2018, p. 5), os tropos argumentativos que a caraterizam se inserem já num conjunto enormemente heterogêneo de contextos e discursos até o ponto de que, como afirmam as editoras de um número especial na revista Signs, "o conservadorismo de gênero tem se convertido em anos recentes na língua franca de uma tendência global" (WALTERS; KAPUR; GRAFF, 2019, p. 541). Favorecida pelo seu caráter transnacional, essa inclui movimentos bastante heterogéneos, desde ataques às liberdades acadêmicas, como a Escola sem Partido no Brasil ou a instauração do chamado "pin parental" na Espanha, até protestos laicos contra a ampliação de direitos reprodutivos, como nas mobilizações recentes de La manif pour tous, em Paris. Ao mesmo tempo, os pânicos morais mobilizados por este conjunto de discursos têm condicionado processos políticos de enorme complexidade, como o processo de paz na Colômbia como explicam Mena-lópez e Aristizábal (2018) - ao tempo que ocupam um lugar fundamental na irrupção das extremas direitas num número crescente de países. Ainda mais, os elementos centrais das retóricas antigênero emergem de formas insuspeitadas em espaços aparentemente antagônicos, como quando uma parte importante do feminismo institucional adota, na Espanha, a retórica vaticana da ameaça da categoria de gênero e das teorias queer como "cabalo de Troia"² das políticas feministas ${ }^{3}$. Sem esquecer, claro está, o apoio de diversos ativismos LGTB às lutas de presidentes da estrema direita contra a "ideologia de gênero", como no caso dos Gays for Trump nos Estados Unidos ou os "Gays com Bolsonaro" no Brasil".

Em cada um desses, como em muitos outros casos, a retórica contra a ameaça do gênero enquanto categoria crítica mutam, como a orquídea de Deleuze, em relação com contextos e campos de relações de poder previamente constituídos, estabelecendo sinergias entre a sua própria força performativa e a dos discursos previamente sedimentados nos espaços pelos que estende a sua influência. Tendo esta relação em conta, surge uma pergunta: pode-se entender a retórica antigênero

\footnotetext{
${ }^{2}$ Ubíqua na atualidade, remonta-se ao menos ao ano 2005, em que o representante da associação contra o aborto Vivir en Familia, de Uruguai, escrevia artigos em que descrevia algo chamado "ideologia de gênero" como "Caballo de Troya cultural" vinculado ao marxismo da "estratégia gramscista" (FERNÁNDEZ, 2005).

${ }^{3}$ Ver especialmente a polêmica em torno da XVI Escuela Feminista Rosario Acuña, celebrada em Gijón em 2019, em que uma série de reconhecidas feministas espanholas alertavam contra o uso da categoria gênero, contra o "transgenerismo" e contra as teorias queer apresentadas justamente como "cabalo de Troia" do feminismo (ver PÉREZ NAVARRO, 2019).

${ }^{4}$ Que se somavam as manifestações de apoio à candidatura de Jair Bolsonaro com lemas como "Por um país sem esse horror chamado "ideologia de gênero", contra o "kit gay" e "pelo respeito à família" (GAY DE DIREITA, 2018).
} 
com independência da sua vocação institucional, isto é, isolada do impulso por regular as políticas do gênero através do poder performativo das políticas públicas, das estruturas administrativas e judiciárias do estado? Não seria, pelo contrário, a característica mais própria do discurso contra a "ideologia de gênero", justamente, a pretensão de colocar o poder performativo do estado ao serviço de organizar a vida generificada - e sexual - do corpo? Pode-se lutar pela abolição do gênero ou da ideologia de gênero sem confiar na ação da polícia, sem a normalização disciplinar dos espaços tanto públicos como privados em que a vida corporal se desenvolve? Fica algo, em fim, da retórica antigênero à margem das cruzadas morais destinadas, sempre já, a se tornar num modelo da ordem pública?

Em relação estreita com essas preocupações, me proponho explorar aqui, em particular, a ideia de que os movimentos antigênero não constituem tanto a defesa de uma ordem moral específica, visto que nem é realmente específica nem aparece nunca por si só, senão que adquirem o seu ar de família na tentativa de se transformar em princípio regulador da ordem pública do estado. Com esse fim, a discussão que segue descreve um caso recente de censura moral em nome da proteção das crianças como uma forma de disciplinamento do espaço da coabitação, como passo prévio para explicar a indistinção entre policiamento moral e securitário do espaço urbano a partir da genealogia europeia da noção de ordem pública.

\section{Censura e Ordem Pública}

No mês de agosto de 2019, o prefeito de Rio proporcionava um exemplo especialmente eloquente das tentativas transnacionais de regular as interseções entre discurso, corpo e espaço, que aqui me preocupam, quando enviava as forças da ordem pública para retirar o comic Vingadores: A cruzada das crianças da Bienal do Livro. Segundo o prefeito, para "proteger às crianças" do encontro com o beijo entre duas personagens do mesmo sexo, "livros assim precisam estar embalados em plástico preto lacrado" (JUCÁ, 2019). A notícia, com ecos da lei anti-propaganda LGBT da Rússia, foi amplamente enquadrada pela mídia no contexto da sucessão de censuras contra a ideologia de gênero no Brasil, teve repercussão internacional e um percurso judiciário que terminou com o Supremo Tribunal Federal censurando a censura em nome do "livre trânsito de ideias" (JIMÉNEZ, 2019). O Tribunal fez, por tanto, o seu trabalho, mostrando a incompatibilidade da tentativa de censura com os princípios de igualdade e não discriminação na legislação de Brasil. Porém, e para entender não tanto este caso concreto de censura, como as cruzadas morais em nome da figura da criança num sentido muito mais geral, convém ter em conta que o que se pretendia aqui, como em noutros casos de censura moral, não era ocultar ou retirar qualquer discurso da esfera pública. Pelo 
contrário, como sublinhava Judith Butler no âmbito de uma discussão sobre a censura estatal do discurso ofensivo:

O desdobramento do discurso ofensivo tem lugar não só na música rap e em várias formas da paródia e da sátira política, mas também na crítica social e política de tais termos, aí onde "o fato de mencionar" esses termos resulta crucial ao respeito dos argumentos dos que vimos falando. Esse desdobramento acontece nos argumentos legais que apelam à intervenção da censura, de fato, a mesma retórica que se condena prolifera invariavelmente no contexto do discurso legal (BUTLER, 1997, p. 14, tradução nossa)

Esse desdobramento do censurado não seria um efeito indesejado. O objeto da censura pode ser, através do próprio ato de censura, recitado, divulgado, amplificado, como o foi o vídeo da chuva dourada na conta de Twitter de Jair Bolsonaro (G1, 2019), sem errar por isso no seu objetivo. Este não teria sido nunca, desde este ponto de vista, censurar o ato fala, de escrita, a performance sexual ou a representação do beijo em si, senão regular o tráfego de ideias numa região muito mais ampla da significação. Nesse sentido, a retórica da defesa das crianças em casos como a censura da mostra Queermuseu (ZEN, 2018) ou, para permanecer no âmbito das retóricas antigênero no Brasil, na ameaça do KIT gay (BALIEIRO, 2018), não pretende a retirada de qualquer mensagem individual do espaço público. A hipervisibilidade do censurado ${ }^{5}$ permitiria, bem ao contrário, uma ação censora muito mais ambiciosa, dirigida contra o que se apresenta como um excesso de porosidade, uma dobra talvez, nas superfícies sexuadas e generificadas que deveriam isolar o espaço público do quanto deveria permanecer oculto na discrição da esfera privada. Para impedir, por tanto, o escandaloso fluxo de significantes através das superfícies espaciais, mas também jurídicas e discursivas que dividem o público do privado, o objeto concreto da censura não precisa ser suprimido senão, pelo contrário, aumentar a sua visibilidade até antecipar todo um universo de censuras possíveis, como se fosse um sinal de tráfego destinado a anunciar o pode circular legitimamente, e o que não, pela esfera pública.

Não se trata aqui, ou não só, da circulação de discursos em sentido restringido. Bem ao contrário, tendo em conta que existe todo um campo de significação aberto através do uso, da estilização, da ação dos corpos, como pôs em evidência o uso da categoria da performatividade ao longo da obra de Judith Butler, poderia existir uma censura moral que não se dirija, sempre já, contra "o escândalo do corpo que fala", como o chama Shoshana Felman? Não seria, justamente, essa dimensão escandalosa "da incongruente mas indissolúvel relação entre linguagem e corpo" (FELMAN, 2003; p. 5), a que permitiria representar mensagens de aparência inofensiva, como a representação do beijo no papel, como projetos de desorganização da vida generificada e sexuada do

\footnotetext{
${ }^{5}$ Como nos vídeos sobre o Queermuseu partilhados pelo mesmo prefeito de Rio, protagonista do caso mais recente da Bienal.
} 
corpo e, no limite, como "pornografia"? Nesse sentido, a censura desse texto incontendível na superfície das páginas adota a forma de uma pergunta ineludível ou, talvez, de uma ameaça: Se as bichas não se podem beijar entre as páginas do comic, o poderiam fazer na rua, à vista de qualquer pessoa? Se o espaço público se define pela acessibilidade por parte de quaisquer corpos, incluindo os corpos - e os olhos - das crianças, pode ou não pode o corpo transviado, como o chama Berenice Bento, circular pelo espaço público? Se sim, com quais limitações, em quais horários, com quais roupas, com quais trejeitos? Com qual tom de pele? E pela quebra de quais regras da coabitação poderia este corpo ser literalmente lacrado em plástico preto, na forma do travesticídio, do assassinato lesbofóbico, ou como foi censurado por vários disparos o corpo de Marcelo Macedo, em Salvador, por se beijar "na frente de pais de família" $(\mathrm{G} 1,2019)$ ?

Neste sentido, quando se trata do policiamento do espaço da coabitação em nome da vulnerabilidade de uma criança imaginada sempre como cisgenêrica e heterossexual, e sempre em risco de deixar de sê-lo, não existe forma eficaz de diferenciar a censura do discurso, o disciplinamento do corpo, e a produção performativa do espaço da coabitação. Encontramo-nos aqui, nesse sentido, num terreno onde a censura pretende domesticar uma escrita geral, no sentido em que Jacques Derrida usa esse termo ${ }^{6}$, como ponte entre as ordens escritas e não escritas da significação na forma de uma censura generalizada ${ }^{7}$. Não seria por acaso, nesse sentido, que essa transição entre o livre trânsito de ideias e o livre trânsito dos corpos implicasse, no caso da Bienal, a intervenção das forças e segurança enviadas pela Secretaria Municipal de Ordem Pública do Rio. Longe de tratar-se aqui de um corpo de censores de artes e espetáculos, como os que podemos encontrar na história de qualquer ditadura, trata-se da Secretaria encarregada de coisas tais como lutar contra o estacionamento dos veículos abandonados, controlar a circulação de vans e reboques irregulares, atuar frente ao barulho excessivo de bares, boates, sinaleiras de garagem ou cultos religiosos e dar resposta, enfim, a qualquer "perturbação do sossego", exceto quando se trata de música funk em cujo caso dever-se-ia chamar diretamente, conforme o que explicam na página da secretaria na web, a Polícia Militar. E essa é, também, a Secretaria envolvida na construção da utopia securitária chamada Rio Mais Seguro, que inclui treinos específicos para identificar "padrões de comportamento que permitam, entre outras coisas, a "identificação de pessoas suspeitas na iminência de executarem crimes" (PREFEITURA, 2019). Em termos gerais, por tanto, a secretaria estaria encarregada do policiamento da circulação de diferentes corpos e sons pelo espaço público da cidade através de

\footnotetext{
6 "Pensamos, pelo contrário, que a língua oral pertence já à escrita", Derrida, 1971, p. 72.

${ }^{7}$ Para uma discussão da transição entre a obra de J. L. Austin, Jacques Derrida e Judith Butler no contexto da discussão do discurso de ódio ver também Quando dizer é violentar: violência linguística e transfobia em comentários online, por Danillo Conceição Pereira Silva ( SILVA, 2019).

${ }^{8}$ Tal como se expressa na pagina web da Secretaria: http://riodejaneiro.rio/web/seop/principal.
} 
estratégias diversas, que incluem uma distribuição da vulnerabilidade à intervenção das forças da ordem pública conforme as variáveis econômicas, raciais, e até religiosas, que permitiriam inclusive a criminalização de determinados corpos com antecedência à execução de quaisquer crimes ${ }^{9}$. Tal pareceria ser, precisamente, a lógica da intervenção das forças da ordem pública na Bienal, incluindo às cruzadas antigênero entre as estratégias para identificar "padrões de comportamento", tais como beijo no papel, que permitam adotar medidas preventivas para evitar a sua execução pública, onde qualquer criança os possa descobrir como um crime possível.

\section{Desordem Pública E Perversão Privada}

A relação entre essa e outras tentativas similares de censura e a sempre imprecisa, polissêmica e, em consequência, arbitrária noção de ordem pública, cuja indeterminação "tem levado os doutrinadores a se referirem a ela como um conceito indeterminado a priori, e mesmo indefinível" (MARQUES, 1995, p. 259), resulta paradigmática das relações entre o estado e a ofensiva antigênero. Especialmente tendo em conta que a retórica antigênero condiciona as condições de aceso ao espaço de aparição na esfera pública das que depende, como lembra Judith Butler em diálogo crítico com Hannah Arendt, a articulação do político em quanto tal. As formas em que os movimentos antigênero pretendem regular o aceso de quaisquer corpos e práticas relacionais ao espaço público variam, claro está, mas sempre dependem da aparente incontestabilidade da distinção entre espaços públicos e privados que, no direito moderno, descansa justamente sobre a noção de ordem pública. A própria Judith Butler lembrava a importância de refletir sobre o caráter político dessa distinção, assim como da necessidade de tomar em conta, nas formas contemporâneas de protesto, aquelas formas de "agência política que emergem precisamente nesses domínios representados como prepolíticos o extrapolíticos [nos termos de Arendt, privados] e que irrompem na esfera de aparição desde o exterior, como o seu exterior, confundindo a distinção entre interior e exterior" (BUTLER, 2015, p. 78, tradução minha). Desse ponto de vista, a retórica antigênero não se limitaria a atualizar nem a propor qualquer espectro de posicionamentos, mais ou menos reconhecivelmente conservadores, sobre a configuração desejável de gêneros, sexualidades, relações de parentesco ou políticas reprodutivas. Ao invés disso, para operar como tais, estas retóricas se inserem nos "mapeamentos mais amplos do segredo e da revelação, do privado e do público" (SEDGWICK, 2007, 26) aos quais se refere

\footnotetext{
${ }^{9}$ A atividade da secretaria envolve assim um panopticismo securitário que atualiza, mediante o uso intensivo de câmaras e aplicativos para dispositivos móveis, aquela perspetiva punitivista burguesa que segundo o Foucault de Vigiar e castigar teria vindo a substituir, ao longo do século XIX, o foco penal no castigo corporal por diferentes mecanismos para corrigir, reformar, normalizar ao delinquente, atuando não tanto sobre o corpo, por ele mesmo, senão sobre "o coração, o pensamento, a vontade, as disposições" (FOUCAULT, 1975 p. 22).
} 
Kosofsky Sedgwick na citação que abre este artigo, em relação portanto com os fundamentos teóricos da democracia liberal e com o poder performativo de uma ampla série de instituições estatais e, também, para-estatais: "Trata-se de uma campanha de longo alcance e, ao mesmo tempo capilar, como escreve Lorenzo Bernini (2018, p. 549). Mais tarde, chamarei a atenção sobre a genealogia do paradigma moral-securitário em que se baseia esta oposição, assim como sobre algumas possibilidades de resistências abertas pela desorganização da distinção subjacente entre interior e exterior à que se refere Butler. Previamente, permita-se-me diferenciar, esquematicamente, a forma como o dispositivo de ordem pública participa na constituição de esta distinção, atuando em ambos lados da mesma, sob a influência do código civil de França em que a noção de ordem pública se introduziu pela primeira vez, e cujo sentido biopolítico tenho explorado com mais detalhes em outros lugares (PÉREZ NAVARRO, 2017, 2018).

No âmbito privado, para começar, no sentido que esta palavra tem na expressão "direito privado", a dimensão biopolítica desse dispositivo jurídico resulta especialmente evidente pela sua forma de participar na organização estatal dos campos do gênero, do parentesco e da reprodução. Da vida jurídica da ordem pública no direito moderno depende, em primeiro lugar, a nossa despossessão de determinados performativos do gênero, no sentido de que é comum considerar que os dados pertencentes ao estado civil, como a marca do sexo legal e o nome próprio, "pertencem à ordem pública" (KÖLER;EHRT, 2016, p. 51) do estado. A este corresponderia, em consequência, a articulação das regras e, também, do conjunto de violências administrativas, como o expressa Dean Spade, que permitem (ou não) a sua alteração dentro do restrito leque de possibilidades fornecidas por cada estado. De maneira similar, invoca-se com frequência a noção de ordem pública para regular as relações de filiação. É por isso que tal noção esteve muito presente nos debates que conduziram à recente negativa do Superior Tribunal de Justiça do Brasil a fornecer reconhecimento legal aos relacionamentos poliafetivos, após o pedido de providências apresentado pela Associação de Direito da Família e das Sucessões, sob o entendimento de que "a ordem pública, no Brasil, impõe a monogamia" (TAVARES DA SILVA, 2018). A decisão, tomada em maio de 2018, honrando assim uma relação entre o dispositivo ordem pública e a monogamia que data das reflexões islamofóbicas do redator do código civil da França, Jean Marie Etienne de Portalis, e que serve também com frequência, nos países ocidentais, para deportar os migrantes polígamos ${ }^{10}$. De maneira similar, as práticas reprodutivas são também objeto de intenso escrutínio em nome da ordem pública, o que leva com frequência a obstáculos administrativos, criminalizações e não reconhecimento de relações de filiação que resultam do uso de determinadas tecnologias reprodutivas em países onde seu aceso é

\footnotetext{
${ }^{10}$ Se bem chegava a conceder, na presentação do código, que "em certos climas e circunstâncias, a poligamia resulta menos revoltante" (PORTALIS, 2004, p. 15; cursivas minhas).
} 
permitido, por parte de cidadãos de países onde estas não estão legalizadas. Em particular, as filiações resultantes do uso de determinadas tecnologias reprodutivas por parte de diferentes grupos inseminações artificiais de mulheres solteiras ou casais lésbicos, ou de doações anônimas de gametas, gestação por substituição - consideram-se contrárias à ordem pública de diferentes países. Assim, com frequência, a ordem pública é invocada para negar o reconhecimento de certidões de nascimento resultantes de exílios reprodutivos a terceiros países, convertendo-se na na garantia transnacional da mesma infraestrutura cisheteromonormativa do parentesco que, sob o lema "Marchemos, Crianças! [Marchons, Enfants!]" (MOUCHONT, 2019), defendia o amplificador social da cruzada vaticana contra a "ideologia de gênero" nas ruas de Paris, La Manif Pour Tous.

No âmbito do direito público, por sua vez, a ordem pública equivale à situação "tranquilidade ou paz nas manifestações da vida cidadã" (ORTEGA, 2003) e à ordem na "convivência coletiva" (REBOLLO, 2019, 304) que permitiria, entre outras coisas, o normal funcionamento das instituições do estado. Esse seria, para dar alguns exemplos do ciclo de protestos de outono de 2019, o sentido da ordem pública cuja perturbação servia para declarar o estado de exceção em resposta às mobilizações do movimento indígena em Ecuador, ou para enviar o exército contra as manifestantes que, ao desafiarem o estado de exceção declarado nas principais cidades de Chile, teriam levado ao país a um estado de guerra, segundo o presidente Piñera. Neste sentido, a ordem pública representa o reverso cotidiano do estado de exceção, cujas implicações biopolíticas tem explorado Giorgio Agambem, e que comumente requer a suspensão da separação de poderes e, desse ponto de vista, do estado de direito; seja de forma explícita, como quando a Ordenança de Regulações de Emergência, legado da época colonial, fornecia com poderes extra-parlamentares à Chefa Executiva de Hong Kong, Carrie Lam, para reprimir as manifestações pela independência e pela democratização desta antiga colônia britânica ou, de forma implícita, isto é, sem declarações formais de qualquer estado de excecionalidade, como quando o estado espanhol condenava, no mesmo mês de outubro, políticos e ativistas sociais da Catalunha por um crime de sedição que constitui também, um crime contra a ordem pública. Delito este último que, em relação direta com o problema da censura estatal, tem raízes na perseguição pré-moderna de formas discursivas e literárias de dissidência política, ao ser entendido como "a noção de incitado por palavras ou escritos o desafeto pelo estado ou pela autoridade constituída" (BREIGHT, 1996, p. 89) ${ }^{11}$. Essa vida pública da ordem pública seria também a que perturbava os manifestantes contra o plebiscito "Viver sem medo" em Montevidéu, para evitar a imposição de um novo paradigma securitário que permitisse aos militares intervir no policiamento quotidiano da ordem pública. Esse último protesto servia, assim, no meio de uma "onda global de

\footnotetext{
${ }^{11}$ Embora tanto o delito de sedição como a própria noção de ordem pública tenham diferentes percursos no direito
} continental e o anglo-saxónico. 
revoltas" (MOLYNEUX, 2019) com "múltiplos focos de indignação" (CASTELLS, 2019) para pôr em evidência que da luta pelo direito pelas condições de aceso, ao trânsito e ao encontro no espaço público depende, como insiste Judith Butler na sua obra recente, a possibilidade de articular quaisquer demandas coletivas pela democratização da democracia. Tendo isso em conta, cabe assinalar que o passo das acampadas que caraterizaram o ciclo das primaveras árabes - desde o movimento 15-M até a Umbrella Revolution em Hong Kong, passando pela ocupação da praça Sintagma em Atenas, a resistência do parque Gezi, em Istambul e as diferentes fases do movimento Occupy - até as mais voláteis e confrontacionais disrupções da "paz social" na presente onda de protestos precisa ser lida à luz da politização das condições de aceso ao espaço público, que inclui como detonantes fatores transversais da economia neoliberal, como o preço do transporte público ou a subida dos combustíveis e também, com consequências ainda por descobrir, o endurecimento autoritário dos dispositivos legislativos, jurídicos e policiais para a manutenção da ordem pública ${ }^{12}$.

\section{A Produção Moral do EsPaÇo}

Tanto na sua vertente pública, na privada, como pela sedimentação histórica de significados que, genealogicamente, as ligam entre si, a ordem pública constitui um denso foco da biopolítica contemporânea. Tendo esta intratável polissemia em conta, surge, porém, uma pergunta que resulta extremamente útil para compreender a territorialização das retóricas antigênero na deriva autoritária de diferentes regimes democráticos: Quais destes tipos de ordem pública ou, se quisermos, que tipo de desordem estava em jogo quando o prefeito de Rio enviava as forças de ordem pública na Bienal? Tratar-se-ia nesse caso da vida pública da ordem pública ou, pelo contrário, do seu sentido privado? A pergunta coloca-nos num terreno ambíguo já que, por um lado, as atividades da Secretaria pertencem claramente às políticas de segurança e ao policiamento do espaço público e estariam enquadradas, portanto, nas biopolíticas da ordem pública no seu sentido propriamente público. Ao mesmo tempo, por outro lado, a classificação dos beijos por graus de legitimidade resulta bem mais próxima ao policiamento moral da esfera privada, na qual a ordem pública aparece como limite aos acordos que os cidadãos podem estabelecer entre eles sem interferência estatal, incluindo as regulações do campo de gênero sem a qual seria impossível, para começar, a identificação do beijo entre personagens do mesmo sexo como problema. Ao mesmo tempo, é justamente no espaço público onde acontece esta perturbação da organização heterossexual dos beijos possíveis. Dessa forma, essa tentativa de censura parece colocar-nos, tanto no seu sentido restrito como no generalizado, numas

\footnotetext{
12 Tendo em conta leis como a lei mordaça na Espanha, como parte da resposta conservadora ao movimento 15-M, ou leis antiterroristas como a que consolidou medidas do Êtat d'Urgence como parte da ordem pública cotidiana na França, ou as leis antiterroristas aprovadas após das Jornadas de Junho no Brasil, entre outras.
} 
coordenadas biopolíticas para as quais a mera alusão ao encontro corporal perturba a ordem pública no mesmo sentido em que o poderia fazer uma revolta popular. Como entender, portanto, essa confusão entre o policiamento da ordem moral (hétero)sexual e o da tranquilidade e o "sossego" no espaço público? Seria este um uso impróprio do dispositivo de ordem pública, que estabelece com esse uma relação meramente arbitrária ou, pelo contrário, de um uso talvez anacrônico, mas que deixa ao descoberto capas profundas do caráter biopolítico da ordem pública? No segundo caso, essas poderiam resultar cruciais para entender o lugar que ocupa o policiamento do corpo perverso na construção disso que chamamos espaço público. Por outro lado, tomar essa sugestão genealógica em conta, não constitui outra foram de perguntar pelas condições em que o corpo perverso encontra-se, sempre já, sujeito a um estado de exceção, tal e como sugere Jasbir Puar em relação com o regímen de excecionalidade sexual e racial ao que se refere como homonacionalismo? Por último, se tomamos a relação corporal e espacial inscrita nos regimes de excecionalidade em conta, em quantos sentidos poderiam os corpos perturbar, pela sua forma de ocupar e circular pelo espaço urbano, essa metáfora central do liberalismo clássico, primeiro, e do neoliberalismo, depois, que é a distinção entre o público e o privado?

Como aproximação ao campo de inquietação do que surgem estas questões, permita-se-me retroceder no tempo, através da cadeia de citações, repetições históricas da fórmula "ordem pública", até começos do século XX em Paris. Em concreto, gostaria de chamar a atenção sobre os motivos da desaparição de uns antigos mictórios públicos que tinham sido instalados no início do século XIX. O que aparece na foto (fig. 1) faz parte de uma série publicada (em 1865) por Charles Malville, cujo trabalho tem o valor histórico de ter documentado a arquitetura da cidade anterior às reformas do Barão Haussman. Isto é, com anterioridade à remodelação brutal do espaço da cidade que abriria os grandes bulevares que expulsaram aclasse obreira das antigas e labirínticas ruas medievais, em nome da otimização do tráfego de veículos, da salubridade e, claro está, da segurança pública. Instalados décadas antes dessas reformas, o vespassianos sobreviveram até as primeiras décadas do século XX, como se se tratasse de cápsulas do tempo procedentes dos inícios da Paris anterior à haussmanização do centro da cidade.

Como se pode conferir na imagem, o vespassiano encontrava-se inserido no espaço urbano e, por vezes, separado deste por um cercado, ou por elementos mais ou menos casuais dos jardins próximos, e que delimitavam uma área de transição em que se intensificava a ordem masculinizada do espaço público. A partir da mesma, e pelo simples jogo arquitetônico entre as superfícies, sem recorrer a portas ou a qualquer outra separação física, o vespassiano produzia um efeito de privacidade que permitia realizar atividades próprias do espaço doméstico. Porém, essas se desenvolviam numa proximidade corporal, precisamente pela sua inserção no espaço público, por vezes indesejada, outras 
procurada, entre diferentes classes sociais e, também, entre diferentes configurações do desejo sexual. A apreensão por indecência pública era, de fato, comum nessas peças do mobiliário urbano, e baseava-se com frequência - como no Rio Mais Seguro - em indícios, variações suspeitosas na coreografia dos corpos que aí se encontravam, complementadas por vezes pela preocupação com diferenças de idade entre quem entrava acompanhado neles. E também, como na Bienal, pela perceção da representação gráfica do repertório de indecências em questão como uma ameaça por si mesma. Assim o denunciava o periodista que, em 1910, como lembra Michal D. Sibalis: "Com que coisas desgraçadas estão cobertas por dentro! Os invertidos não estão satisfeitos com fazer delas um dos seus lugares de encontro. Escrevem nelas, usando a publicidade para converter a outros por contágio!" (SIBALIS, 1999, p. 20, grifo meu).

Figura 1 - Vespassiano

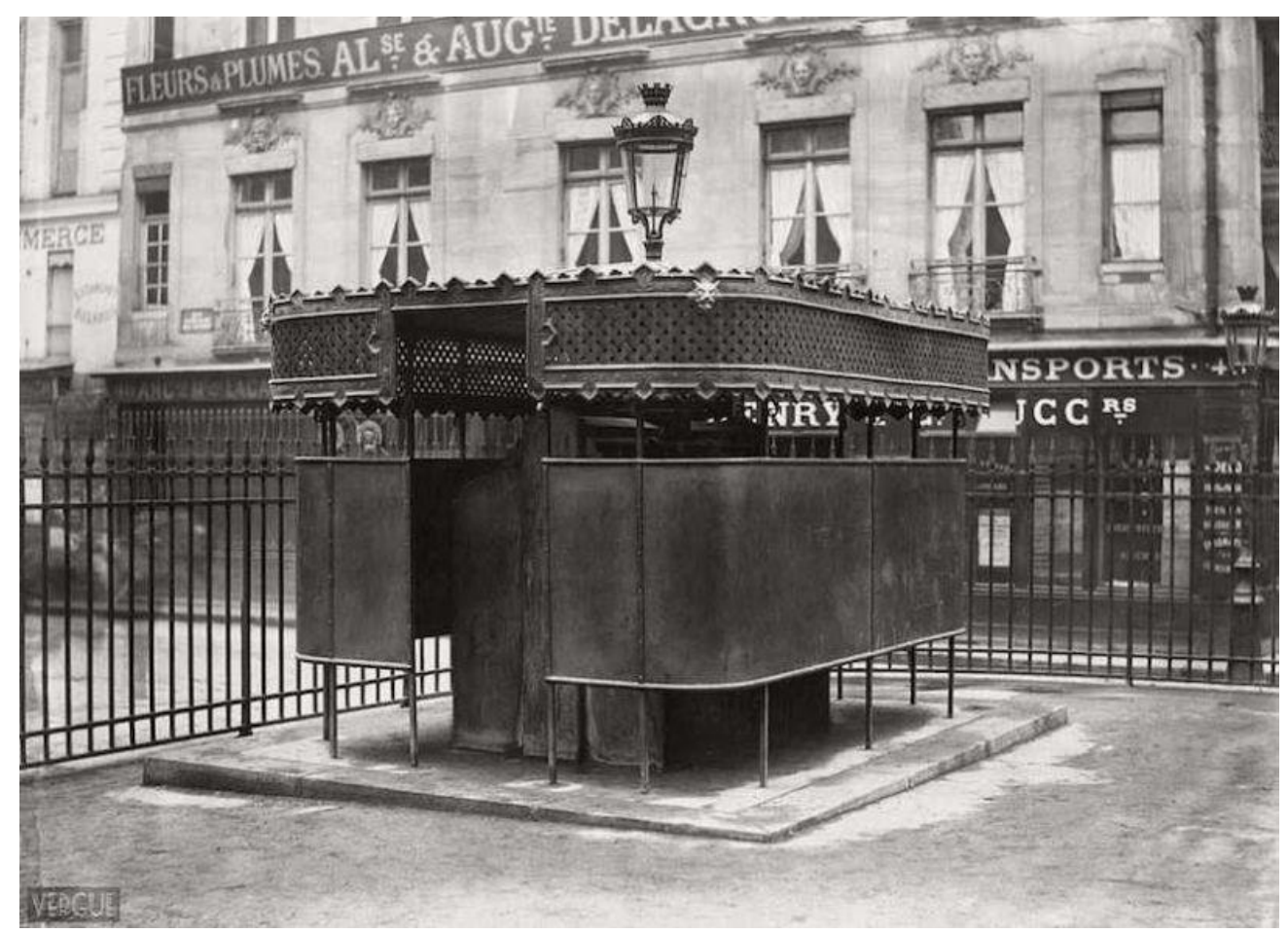

Fonte: (C) Charles Marville

O policiamento dos vespassianos ocupa, por tanto, um lugar preciso no processo de privatização da homossexualidade na França do século XIX, complementar à construção da criminalização e da patologização da homossexualidade pelo discurso jurídico-psiquiátrico. Porém, no inicio do século XX, esse policiamento da coabitação no vespassiano tornou-se insuficiente para o disciplinamento sexual do espaço urbano, e seria complementado com um disciplinamento que não atingiria já, ou não só, os corpos dos invertidos senão, preventivamente, aos próprios espaços 
arquitetónicos da cidade. Assim, os próprios mictórios começaram a ser retirados até praticamente desaparecer das ruas ao longo do século XX. Aduziam-se, também, motivos de salubridade, mas que resultavam indistinguíveis, segundo oficiais de policia da época, "dos motivos de ordem pública, pelo uso impróprio que [os homossexuais] faziam deles, causando moléstias aos vizinhos" (SIBALIS, 1999, p. 23). Consumava-se assim um longo processo de haussmanização dos espaços da cidade heterossexual com a purificação da desordem sexual, no sentido ritualizado em que usa esse termo Mary Douglas, enquadrado na crença de que "certos valores morais são protegidos e certas regras sociais definidas por crenças em contágios perigosos, por exemplo, quando o olhar ou o toque de um adúltero é considerado a causa da enfermidade dos seus vizinhos ou dos seus filhos" (DOUGLAS, 1991, p. 7). Com esse objetivo de consolidação da ordem moral, o poder performativo da ordem pública dirigiu-se contra um conjunto de estruturas que, como se de garrafas de Klein cujas superfícies são interiores e exteriores ao mesmo tempo - se tratasse, faziam com que a distinção público-privado entrasse em crise. Nesse sentido, a expulsão dos vespassianos da cidade reflete a gestação de um paradigma da ordem pública fundamentado na securitização e segregação social do espaço urbano iniciada por Haussman e cuja influência chega até tempos muito mais recentes ${ }^{13}$. $\mathrm{O}$ que este "momento banheirão", se quisermos, da genealogia europeia da ordem pública coloaria em relevo seria um denso núcleo biopolítico no que resultam indistinguíveis a reorganização do espaço urbano, o disciplinamento do corpo e a censura do discurso abjeto. Esse teria perdurado, em formas mais ou menos reconhecíveis, ao longo da história da sua expansão geográfica e territorial, reaparecendo com força no encontro das retóricas antigênero com diversas formas do autoritarismo politico, tais como a tentativa de censura na Bienal.

Convém ter em conta, em qualquer caso, que a disseminação das biopolíticas da ordem pública não depende só de momentos singulares, como a escrita de tal ou qual peça da legislação, senão que deve ser entendida como uma conversa mantida ao longo do tempo. Uma conversa que não é, e nunca foi, horizontal, no entanto acontece num cenário profundamente marcado pelos sistemas imperiais e coloniais. Assim o punha em evidencia, por exemplo, o jurista brasileiro Clóvis Beviláqua, quando refletia em Recife, a finais do século XIX, sobre "a influência continua que as legislações dos povos mais cultos são chamados a exercer sobre os demais, já pela superioridade que impõe a sua cultura, já pelas leis da imitação" (BEVILÁQUA, 1895, 142). Uns anos depois, inspirado pelo código civil da França - em que se inseria a noção jurídica de ordem pública na legislação de Brasil - o próprio Beviláqua escreveria no primeiro Código Civil de Brasil, vigente desde 1916, que

\footnotetext{
${ }^{13}$ Assim o colocaria em relevo Samuel R. Delany, na sua descrição da destruição das contraculturas sexuais na cidade de Nova Iorque nos anos oitenta, e o mesmo poderíamos pensar da reforma neoliberal do parque Gezi, em Istambul, com o seu efeito de despossessão e desterritorialização para diferentes comunidades étnicas e dissidências sexogenêricas. 
"as disposições e convenções particulares, não terão eficácia, quando ofenderem à ordem pública $e$ os bons costumes" ${ }^{14}$. Dessa forma, o Brasil distanciava-se da herança legislativa portuguesa para imitar - como o fizeram a quase totalidade dos sistemas jurídicos da Europa, América Latina e até Japão - a contiguidade estabelecida entre a manutenção da ordem pública e o policiamento de uns "bons costumes" vinculado à ordem moral, não escrita, da vida social, ligada também à organização dos campos do gênero e da sexualidade. Pouco surpreende nesse sentido que, na mesma época, essa importação da ordem pública fosse acompanhada, no Brasil, pela importação da figura francesa, branca e burguesa da bicha, "que invade o pensamento de juristas e médicos brasileiros no final do século XIX", como escreve Megg Rayara Gomes de Oliveira (2018, p. 169); e que muito contribuiria para privatizar, precisamente, os "frescos, putos e viados as Joaninas do Rossio" (p. 168), no Rio de Janeiro. Dessa forma, tanto na França como no Brasil, onde a homossexualidade não era considerada crime desde inícios do século XIX sempre que fosse praticada em privado, a expulsão do corpo perverso do espaço urbano em nome da ordem pública converter-se-ia numa parte importante da negociação do que conta como ordem, como espaço público, e como perversão privada.

\section{CONSIDERAÇÕES FINAIS}

As biopolíticas da ordem pública, com a transição entre o disciplinamento da ordem do espaço da coabitação e o disciplinamento do corpo que implicam, constituem um só terreno sobre o qual as retóricas antigênero disseminam a sua própria força performativa. Essa disseminação pode ser entendida como um processo de territorialização discursiva, a condição de entender que não se produz só no terreno discursivo em sentido restrito, senão no âmbito de uma escrita generalizada que implica, entre outros, o âmbito institucional, as políticas de segurança pública, e formas concretas de policiamento do espaço urbano e de constituição da distinção público-privado. Isso seria o que acontece, ao menos, toda vez que as retóricas antigênero são instrumentalizadas "para consolidar o poder do Estado" (PATERNOTTE, 2018, p. 515). O que sugere a aproximação genealógica à noção de ordem pública, em concreto, seria que a defesa de um rígido sistema moral em nome da luta contra algo chamado "ideologia de gênero" vinculam a expansão da direita global com diferentes temporalidades das políticas estatais, incluindo não só a nostalgia das ditaduras, como sucede em muitos lugares da América Latina e da Europa do Sul, senão também ao seu aparente oposto, isto é, a divisão jurídica e moral entre o público e o privado que está na mesma base da construção da democracia liberal.

\footnotetext{
${ }^{14}$ Código Civil dos Estados Unidos do Brasi, lei no 3.071, de $1^{\circ}$ de janeiro de 1916, art. 17.
} 
Nesse contexto, a figura criança opera como dobradiça entre as retóricas antigênero e os discursos securitários postos ao serviço de restringir o campo do possível na esfera pública. A condição de entender, claro está, que a criança que aparece em discursos como o do prefeito de Rio não é a criança real que lê um comic na Bienal, senão a criança como personificação, nas palavras de Lee Edelman, do "telos da ordem e consagração da figura para quem essa ordem tem que ser mantida em perpetua confiança" (1998, p. 21); nas de Judith Butler - num famoso ensaio que incluía a seção ilustrativamente intitulada A pobre criança e o destino da nação - da criança entendida como "espaço de transmissão cultural" (2002, p. 35); ou ainda, nas de Paul B. Preciado, como "artefacto biopolítico que garante a normalização do adulto" (2013, p. 98). Nesse sentido, a ocupação das ruas por coligações das dissidências feministas, sexuais e de gênero, como no caso do movimento \#Elenão, podem ser lidas como enérgicos movimentos de contestação aos efeitos disciplinares deste dispositivo sobre as superfícies sexuadas, generificadas, racializadas que dividem o público do privado. Incluindo, como consequência, o impulso pela desorganização das hierarquizadas divisões entre o espaço do comum e o espaço doméstico, o espaço da produção e o da reprodução, a hegemonia moral da perversão privada, a academia do ativismo, o ativismo de classe e as lutas das minorias, o material e o meramente cultural. Todas essas oposições resultam afetadas pelos encontros e deslocamentos dos corpos nos quais, explica Butler (2002, p. 76), "acontece algo mais", mostrando

o que significa deslocar-se pelo espaço de uma forma que põe em causa a distinção entre o público e o privado, de forma que os corpos na sua pluralidade reclamam o público, encontram e produzem o que é público através da apropriação e a reconfiguração dos entornos materiais (BUTLER, 2002, p. 76).

Isso seria o tipo de apropriação que se pretenderia evitar com diferentes formas de censura moral, desde os vespassianos até a Bienal. E seria, também, o caso de encontros que reivindicam, simplesmente, o direito ao encontro, como na manifestação contra a censura na Bienal, ou nas denúncias da violência sexual perpetrada por parte das forças encarregadas da manutenção da ordem pública, como denunciaram o movimento \#metoo em Hong Kong e, também, a disseminação global da performance do grupo Las Tesis, do Chile. De maneira similar, podemos pensar nas assembleias queer e transfeministas nos movimentos Occupy, nos protestos contra a "cura gay" nas Jornadas de Junho, ou na presença de Act Up nos protestos dos coletes amarelos, entre outras formas inesperadas de irrupção dos corpos no espaço público para produzir alternativas aos geométricos bulevares morais em que descansam tanto as retóricas antigênero como as derivas autoritárias das biopolíticas da ordem pública. 


\section{REFERÊNCIAS}

BALIEIRO, F. "Don't mess with my kids": Building the moral panic of the child under threat. Cadernos Pagu, Campinas, n. 53, 2018. DOI: https://doi.org/10.1590/18094449201800530006

BEVILÁQUA, C. Resumo das lições de legislação comparada sobre o direito privado. Revista Brazileira, Recife, n. 1, p. 139-146, 1893.

BREIGHT, C. Surveillance, Militarism and Drama in the Elizabethan Era. New York: St. Martin's Press, 1996.

BUTLER, J. Excitable Speech. A politics of the Performative. New York and London: Routledge, 1997.

BUTLER, J. Is Kinship Always Already Heterosexual? Differences: A Journal of Feminist Cultural Studies, Durham, n. 13, v. 1, p. 14-44, 2002.

CASTELLS, M. Explosiones sociales, La Vanguardia, Barcelona, 25 out. 2019. Disponível em https://www.lavanguardia.com/opinion/20191025/471186542407/explosiones-sociales.html. Acesso em: 17 dez. 2019.

DERRIDA, J. De la gramatología. México D.F.: Siglo XXI Editores, 1971.

DOUGLAS, M. Pureza e perigo: ensaio sobre as noções de poluição e tabu. Lisboa: Edições 70, 1991.

EDELMAN, L. The Future is Kid Stuff: Queer Theory, Disidentification, and the Dead Drive. Narrative. Ohio, v. 6, n. 1, p. 18-30, 1998.

FELMAN, S. The scandal of the speaking body: Don Juan with J.L. Austin, or seduction in two languages. Stanford: Stanford University Press, 2003.

FERNÁNDEZ, T. N., Ideología de género: caballo de troya cultural, Catholic.net, 9 de Dez. de 2005. Disponível em https://es.catholic.net/op/articulos/17448/cat/852/ideologia-de-genero-caballode-troya-cultural.html. Acesso em: 17 dez. 2019.

GAY DE DIREITA. Manifestação dos Gays Com Bolsonaro, Facebook, 30 set. 2019. Disponível em https://www.facebook.com/events/av-paulista-X-alamedacampinas/manifesta\%C3\%A7\%C3\%A3o-dos-gays-com-bolsonaro/340423483197543/. Acesso em: 17 dez. 2019.

GLOBO. Posts de Bolsonaro com pornografia e "golden shower" repercutem na imprensa internacional, Globo.com, 6 de março de 2019. Disponível em https://g1.globo.com/mundo/noticia/2019/03/06/posts-de-bolsonaro-com-pornografia-e-goldenshower-repercutem-na-imprensa-internacional.ghtml. Acesso em: 17 dez. 2019.

GLOBO. Suspeitos de envolvimento na tentativa de homicídio contra homem que beijou outro rapaz se apresentam e são ouvidos na BA, Globo.com, 23 de Set. de 2019. Disponível em https://g1.globo.com/ba/bahia/noticia/2019/10/23/suspeitos-de-envolvimento-na-tentativa-dehomicidio-contra-homem-que-beijou-outro-rapaz-se-apresentam-e-sao-ouvidos-na-ba.ghtml. Acesso em: 17 dez. 2019. 
HIGGS, D. Queer Sites: Gay Urban Histories Since 1600. London e Nova Iorque: Routlegde. 1999.

JIMÉNEZ, C. STF proíbe censura de livros no Rio e dá recado contra discriminação. El País, 9 set. 2019. Disponível em https://brasil.elpais.com/brasil/2019/09/08/politica/1567961873_908783.html. Acesso em: 17 dez. 2019.

JUCÁ, B. Justiça veta censura homofóbica de Crivella na Bienal do Livro do Rio, El País, 7 de setembro, 2019, https://brasil.elpais.com/brasil/2019/09/06/politica/1567794692_253126.html

KÖLER, R.; EHRT, J. Legal Gender Recognition in Europe. Transgender Europe (TGEU) - Rights, Equality and Citizenship Programme of the European Union, nov. 2016. Diponível em https://tgeu.org/toolkit_legal_gender_recognition_in_europe/. Acesso em: 17 dez. 2019.

KOSOFSKY SEDGWICK, E. A epistemologia do armário. Cadernos Pagu, Campinas, v. 28, p. 19-54, 2007.

MARQUES, J. C. Ordem pública, ordem privada e bem comum. Conceito e extensão nos direitos nacional e internacional. Revista Jurídica Cesumar - Mestrado. Margingar, v. 2, n. 1, 245-268, 1995.

MENA-LÓPEZ, M.; ARISTIZÁBAL, Fidel Mauricio. Las falacias discursivas en torno a la ideología de género. Ex Aequo, v. 37, p. 19-31, 2018. Disponível em https://doi.org/10.22355/exaequo.2018.37.02. Acesso em: 17 dez. 2019.

MOLYNEUX, J. A New Wave of Social Revolt?. Rebel, The New Socialist Website, 6 nov. 2019. Disponível em http://www.rebelnews.ie/2019/11/06/a-new-mass-wave-of-global-revolt/. Acesso em: 17 dez. 2019.

MOUCHONT, F.. Manif anti-PMA pour toutes: «On tiendra plus longtemps qu'en 2013», Le Parisienne. Paris, 6 out. 2019. Disponível em http://www.leparisien.fr/societe/manif-anti-pmapour-toutes-on-tiendra-plus-longtemps-qu-en-2013-06-10-2019-8167368.php. Acesso em: 17 dez. 2019.

OLIVEIRA, M. R. G. Trejeitos e trajetos de gayzinhos afeminados, viadinhos e bichinhas pretas na educação, Periódicus, Salvador, v. 9, n.1, p. 161-191, 2018.

ORTEGA, Miguel Álvarez. Orden público: unidad axiológica, espacio europeo. Anuario de Derecho Europeo. Sevilla, v. 3, p. 15-45, 2003.

PATERNOTTE, D. "Ideología de género" en movimiento. Psicologia Política. São Paulo, v. 18, n. 43, p. 503-523, 2018.

PÉREZ NAVARRO, P. Biocriminality and the Borders of Public Order. In JUSTO, José Miranda; ALEXANDRE LIMA, Paulo; SILVA, Fernando (Eds.). Questioning the Oneness of Philosophy. Lisbon: Centre for Philosophy University of Lisbon, p. 203-215, 2018.

PÉREZ NAVARRO, P. Cisheteromonormatividad y Orden Público@. In: OLIVEIRA, João Manuel; AMÂNCIO, Ligia (ed.). Géneros e sexualidades: intersecções e tangentes. Lisboa: CISIUL, p. 87-11, 2017. 
PÉREZ NAVARRO, P. Del texto al sexo. Judith Butler y la performatividad. Madrid: Egales, 2008.

PÉREZ NAVARRO, P. Feminismo Trans-excluyente e teoría queer: replica a Alicia Miyares, Orgullos Críticos, 25 de Julho de 2019, Disponível em https://orgulloscriticos.wordpress.com/2019/07/25/feminismo-trans-excluyente-y-teoria-queerreplica-a-alicia-miyares/. Acesso em: 17 dez. 2019.

PÉREZ NAVARRO, P. Márgenes del género: Judith Butler y la deconstrucción. In: PERETTI, Cristina; VELASCO, Eduardo (ed.), Conjunciones. Derrida y compañía. Madrid: Dykinson, p. 357$381,2017$.

PORTALIS, J. M. É. Discours préliminaire du premier projet de Code civil (1801), Bordeaux : Éditions Confluences, 2004.

PREARO, M.; GARBAGNOLI, Sara. La croisade anti-genre: Du Vatican aux Manif pour tous (Petite encyclopédie critique). Paris: Éditions Textuel, 2018.

PRECIADO, P. B. Quem defende a criança queer? Jangada, Viçosa, v. 1, p. 96-99, 2013.

PREFEITURA RIO, O que é Rio Mais Seguro, Prefeitura de Rio, Rio de Janeiro. Disponível em http://maisseguro.rio/. Acesso em: $17 \mathrm{dez} .2019$.

REBOLLO VARGAS, R. Sedición (Delito de). EUNOMÍA. Revista En Cultura de La Legalidad, Madrid, v. 17, Out. 2019/mar. 2020. Disponível em https://doi.org/10.20318/eunomia.2019.5035. Acesso em: 17 dez. 2019.

SILVA, D. da C. P. Quando dizer é violentar. Violência linguística e transfobia em comentários online. Salvador: Devires, 2019.

TAVARES DA SILVA, R. B. CNJ deve julgar amanhã o pedido de providências da ADFAS. Associação de Direito Da Família e Das Sucessões, 21 de maio de 2018. Disponível em http://adfas.org.br/2018/05/21/cnj-deve-julgar-amanha-22-05-o-pedido-de-providencias-da-adfas/.. Acesso em: 17 dez. 2019.

WALTERS, S. D.; KAPUR, A.; GRAFF, R. Gender and the Rise of the Global Right. Signs, Chicago, v. 44, n. 3, p. 1-20, 2019. https://doi.org/10.1086/701152.

ZEN, R. L. A supressão do outro no episódio do Queermuseu: A liberdade de expressão sob coerção e o que pode o artivismo queer. Palíndromo, Florianópolis, v. 10, n. 21, p. 130-154, 2018. 